\title{
STATISTICS ANXIETY AND WORRY: THE ROLES OF WORRY BELIEFS, NEGATIVE PROBLEM ORIENTATION, AND COGNITIVE AVOIDANCE
}

\author{
AMANDA S. WILLIAMS \\ Texas Tech University \\ a.williams@ttu.edu
}

\begin{abstract}
Statistics anxiety is a common problem for graduate students. This study explores the multivariate relationship between a set of worry-related variables and six types of statistics anxiety. Canonical correlation analysis indicates a significant relationship between the two sets of variables. Findings suggest that students who are more intolerant of uncertainty, believe that worry is beneficial, possess a negative approach to problems, and utilize cognitive avoidance as a coping strategy are more likely to have higher levels of the six types of statistics anxiety. These results highlight the complexity of graduate students' statistics anxiety. Suggestions for intervention are discussed.
\end{abstract}

Keywords: Statistics education research; Affect; Graduate students

\section{INTRODUCTION}

Statistics anxiety remains a problem for most college students, affecting not only their performance (Chiesi \& Primi, 2010; DeVaney, 2010; Keeley, Zayac, \& Correia, 2008; Lalonde \& Gardner, 1993; Murtonen \& Lehtinen, 2003; Onwuegbuzie \& Seaman, 1995; Zanakis \& Valenzi, 1997), but also their self-perceptions (Blalock, 1987; Dillon, 1982; Onwuegbuzie, 2000c; Perepiczka, Chandler, \& Becerra, 2011), and their confidence and abilities in statistics and research situations (Onwuegbuzie, 1995, 1997). Estimates of students afflicted with this type of anxiety run as high as $80 \%$ (Onwuegbuzie, 2004), and though some solutions have been offered (Dillon, 1982; Pan \& Tang, 2005; Schacht \& Stewart, 1990; Williams, 2010; Wilson, 1996, 1999), the problem persists.

Among researchers who have studied statistics anxiety, the tendency in the past has been to approach the problem in isolation, focusing on how the phenomena relate in a singular nature to student characteristics such as gender, age, or nationality (Bell, 1998, 2004; Benson, 1989; Benson, Bandalos, \& Hutchinson, 1994; Demaria-Mitton, 1987), instructional methods (DeVaney, 2010; Onwuegbuzie \& Seaman, 1995; Pan \& Tang, 2005), and student attitudes (Onwuegbuzie, 2000a; Roberts \& Saxe, 1982; Wise, 1985; Zanakis \& Valenzi, 1997). Others have taken a different approach to the study of statistics anxiety by considering affective factors such as hope (Onwuegbuzie, 1998), perfectionism (Onwuegbuzie \& Daley, 1999), and procrastination (Onwuegbuzie, 2000b).

This is similar to those who examine general anxiety where the tendency has been to study individual variables of affect (Borkovec, Hazlett-Stevens, \& Diaz, 1999; Borkovec \& Roemer, 1995; Ladouceur, Blais, Freeston, \& Dugas, 1998; Ruscio \& Borkovec, 2004), and though this is a necessary and important step in understanding the factors associated with anxiety, one team of researchers in particular (Koerner \& Dugas, 2006)

Statistics Education Research Journal, 14(2), 53-75 http://iase-web.org/Publications.php?p=SERJ (C) International Association for Statistical Education (IASE/ISI), November, 2015 
proposes that anxiety is best understood in the context of a combination of affective components. According to them, anxiety is inseparable from worry, intolerance of uncertainty, positive beliefs about worry, negative problem orientation, and cognitive avoidance. If this is the case, then more specific forms of anxiety can also be expected to share a combined relationship with these variables, including statistics anxiety.

\section{REVIEW OF THE LITERATURE}

\subsection{STATISTICS ANXIETY}

Anxiety is an uncontrollable emotional response to a perceived threat (Rachman, 2004). According to Rachman, cognition and emotion are intertwined, but even the most intense effort to control anxiety through cognition is normally unsuccessful. Statistics anxiety is an emotional response to situations involving statistics in any form or at any level, and is believed to be a common problem for students with estimates of between two-thirds and four-fifths of students being affected (Onwuegbuzie \& Wilson, 2003). The resulting avoidance of statistics courses, often until the end of their degree programs, leaves students less than ideally prepared for their coursework (Onwuegbuzie, 2004; Roberts \& Bilderback, 1980). Zeidner (1991) described statistics anxiety as "a form of performance anxiety characterized by extensive worry, intrusive thoughts, mental disorganization, tension, and physiological arousal" that afflicts students when they come into contact with statistics content or situations.

Such unpleasant experiences and feelings were well documented in Onwuegbuzie, DaRos, and Ryan (1997), a qualitative study designed to explore students' experiences in an introductory statistics class. In analyzing journal writings, these authors found that students often experienced physical symptoms such as dry mouth, headaches, sweating, increased heart rate, and tight throat, and emotional and cognitive symptoms such as worry, frustration, learned helplessness, uncertainty, and hostility. A participant-observer who was enrolled in the class recorded incidents of students' anxious behaviors such as nail biting, crying, irritability, and angry outbursts. Strong feelings such as these normally cause people to avoid the provoking situation as much as possible (Rachman, 2004), so it is understandable that students' procrastination in enrolling in statistics courses is so common.

Anxiety for statistics students may be more severe than anxiety experienced by students in other courses. Dykeman (2011) explored this premise in a sample of 57 graduate education students. In comparing 37 students in statistics courses with 20 students in other education courses, students were asked to rate their general anxiety about the course they were in as well as their self-efficacy for doing well in the course. An independent-measures $t$-test showed that students in the statistics course reported significantly higher levels of academic anxiety $(t(55)=2.155, p<0.05)$ and significantly lower self-efficacy for the course $(t(55)=2.898, p<0.01)$ than students in other courses. Why this increased anxiety in statistics class? Pan and Tang (2005) found evidence that various in-class factors were major contributors to higher levels of anxiety for statistics students.

These authors conducted a focus group with seven graduate students enrolled in statistics and asked what they believed generated the most anxiety for them. Beyond a fear of mathematics, an important anxiety inducer was the attitude of their instructor. Some students said they felt the instructor did not care how they were doing in the course, and another said she was afraid to ask a question because she had seen others ridiculed. The pace of the course was also anxiety-provoking for these students as they felt they 
needed more time to cover each topic. Further, these students were unable to see any connection between statistics and everyday life, and this disconnect also increased their anxiety.

Anxiety about statistics has frequently been shown to affect students' academic outcomes. For example, Fitzgerald and Jurs (1996) inquired into the influence of role conflict, statistics anxiety, and demographic variables on achievement in a pass/fail statistics class. One-hundred-nine graduate students were asked whether they were working full or part time, and whether they were attending classes full or part-time, as a means for identifying those who fit the criteria of role-conflicted. Those who were fulltime students with part-time jobs were deemed optimal, while students with other combinations of work and school obligations were categorized as role-conflicted. Moreover, the students were asked to report on their levels of statistics anxiety and demographic variables of age and number of previous mathematics courses.

Logistic regression was used to categorize students as either pass or fail, based on the predictor variables of role-conflicted status, statistics anxiety, previous math courses, and age, with the resulting model being significant $(\operatorname{LR}(3)=30.68, p<0.05)$. Further, it was found that statistics anxiety had the highest partial correlation with achievement $(R=$ $0.22)$, with age $(R=0.15)$, role-conflicted status $(R=0.14)$, and number of previous mathematics courses $(R=0.05)$ following. The authors report that the overall $R^{2}$ of the model was 0.50 , meaning that the variance in the four predictor variables was associated with $50 \%$ of the variance in statistics achievement.

Onwuegbuzie and Daley (1996) also examined the relationship between statistics anxiety and student achievement; their focus, however, was on skills used to cope with their anxiety. These authors utilized a sample of 26 graduate students enrolled in an intermediate statistics course to consider the effects on achievement of two types of anxiety-related coping skills: study coping skills and exam-taking coping skills. Study coping skills involve the ability to effectively deal with anxiety in order to study effectively. Students who are highly anxious tend to have less of this coping skill, leading them to absorb or understand less of the material they are studying. Exam-taking coping skills involve the ability to manage one's anxiety while in a testing situation. Students who are highly anxious tend to have less of this coping skill, leading them to be less able to retrieve the information they have learned.

With the purpose of comparing these two types of coping skills and their effects on test performance, the authors gave the students a questionnaire designed to measure their coping skills and their statistics anxiety. The students were then randomly assigned to two testing conditions: timed (90 minutes) and untimed. The authors report the correlation between the students' scores on study coping skills and exam-taking coping skills was not significant $(r=0.29, p>0.05)$, indicating that the two instruments measured different coping skill sets. It was also found that both factors were significant for both target variables: study coping skills were related to test scores $(r=0.47, p<$ $0.01)$ and test anxiety $(r=-0.41, p<0.05)$; exam-taking coping skills was also related to test scores $(r=0.51, p<0.05)$ and test anxiety $(r=-0.48, p<0.05)$. These results show that students with greater skills of both types tend to have lower levels of test anxiety. Further, the data indicate that study coping skills were significantly related to the anxiety dimensions of worth of statistics $(r=-0.48, p<0.05)$ and fear of asking for help $(r=$ $-0.43, p<0.05$ ), while exam-taking coping skills were significantly related to the dimensions of interpretation anxiety $(r=-0.58, p<0.01)$ and computation self-concept $(r$ $=-0.49, p<0.05$ ). These results show that students who are highly anxious tend to have poorer coping skills in both areas. Multiple regression analyses showed that both types of coping strategies were associated with $60.2 \%$ of the variance in test anxiety. 
Additionally, two-way analysis of covariance revealed a significant main effect for exam-taking coping skills on achievement $(F(1,17)=28.67, p<0.01)$, indicating that students with better exam-taking coping skills had better test performance $(r=0.72, p<$ 0.01). A significant interaction between testing condition and exam-taking coping skills was also found $(F(1,7)=5.57, p<0.05)$, indicating that those with poorer exam-taking coping skills were affected adversely by the timed testing condition. A significant main effect for study coping skills was also found $(F(1,17)=21.55, p<0.01)$, suggesting that students with better study coping skills had better test grades $(r=0.57, p<0.01)$. There was no significant interaction between study coping skills and testing condition, indicating that regardless of students' study coping skills, whether the test was timed or not had no effect on their outcomes. There was, however, a main effect for testing condition $(F(1,17)=5.61, \mathrm{p}<0.05)$ indicating that those in the timed condition scored lower on their test than those in the untimed condition. An equally interesting finding in this study was that there was no significant relationship between the actual time to complete the test and performance for both the timed condition $(r=0.15, p>0.05)$ and the untimed condition $(r=0.19, p>0.05)$. It appears that - within the given time constraints - actual time used to finish the tasks has no influence on achievement.

More recent studies continued to highlight the relationship between statistics anxiety and student achievement. For example, Keeley, Zayac, and Correia (2008) studied the form of the relationship between anxiety and achievement in a sample of 38 undergraduate students. Based on the Yerkes-Dodson law, which states there is a beneficial level of anxiety in terms of optimal performance, the authors were interested in finding whether this applied to statistics performance. The expectation was that students' need for achievement, a form of motivation, would moderate the relationship between anxiety and performance in that those with a higher need for achievement would use their anxiety toward course goals while those with lower need for achievement would not. Students were given a measure of statistics anxiety as well as a measure of need for achievement, and six exams over the course of a semester. The authors hypothesized that low and high anxiety levels would result in lower test scores, while moderate anxiety levels would result in higher test scores.

Scores on the first two tests were not significantly related to anxiety scores, but with the progression of the semester the relationship between them grew stronger with the expected curvilinear relationships as hypothesized. As an example, a quadratic equation showed a significant curvilinear relationship between scores on Test 6 and test anxiety ( $r$ $=0.15, F(2,59)=5.31, p=0.008)$, worth of statistics $(r=0.25, F(2,59)=9.83$, $p$-value $<$ $0.001)$, and interpretation anxiety $(r=0.18, F(2,58)=6.49, p=0.003)$. Even though the expected moderating effect of need for achievement was not shown to be significantly related to either statistics anxiety or students test scores, the results of this study appear to support the idea that there could be an optimal level of anxiety for students in terms of their achievement.

In another recent study with a focus on achievement, Zare, Rastegar, and Hosseini (2011) proposed that the relationship between achievement goals and students' achievement in statistics courses may be moderated by statistics anxiety and self-efficacy. A sample of 323 Iranian students was given a test instrument for each of six types of statistics anxiety (see the description of the STARS instrument in section 3.2); further, the students were administered a test instrument on statistics self-efficacy and on three types of achievement goals. End-of-course grades served as the achievement variable. Path analysis showed that both avoidance-performance ( $r=0.30, p<0.05)$ and approachperformance goals $(r=0.15, p<0.05)$ were significantly related to statistics anxiety, and statistics anxiety was significantly related to achievement $(r=-0.25, p<0.05)$. Also, 
approach-performance goals $(r=-0.15, p<0.05)$ and mastery goals $(r=0.33, p<0.05)$ were significantly related to self-efficacy, and self-efficacy was significantly related to achievement $(r=0.40, p<0.05)$. These findings support the authors' assertion that the relationship between achievement goals and achievement outcomes in statistics courses may be moderated by statistics anxiety and self-efficacy.

Comparatively, Onwuegbuzie (2003) utilized a sample of 130 graduate students to develop a model for predicting statistics students' outcomes based upon the cognitive variables of study habits and expectation for success, the affective variables of statistics anxiety and research anxiety, and personal variables of course load and previous mathematics classes. Through path analysis, Onwuegbuzie found a direct negative effect of statistics anxiety on achievement $(r=-0.18, p<0.05)$, with a direct positive effect of expectation on achievement $(r=0.19, p<0.05)$. The author explains this complicated finding as the student's initial expectation for success, which leads to higher anxiety, which then leads the student to have a reduced level of expectation for success. The author reports that statistics anxiety and expectation were also found to mediate the relationship between the cognitive and personal variables studied and achievement. According to these results, students' expectation for success in statistics class can enhance their achievement, but may also have a detrimental effect due to the accompanying increase in anxiety, while anxiety itself impedes achievement.

Chiesi and Primi (2010) conducted a similar study involving 487 undergraduate students, wherein they aimed to model the effects of attitude toward statistics, mathematical ability, and statistics anxiety on student achievement. The authors found that mathematical ability had a direct negative effect on anxiety $(r=-0.18, p<0.01)$ and a direct positive effect on achievement $(r=0.71, p<0.01)$. They also found a direct negative effect of anxiety on end-of-course attitude $(r=-0.38, p<0.01)$, which had a direct positive effect on achievement $(r=0.21, p<0.01)$. These results indicate that lower anxiety is associated with better end-of-course attitudes toward statistics, and with better achievement outcomes.

As evidenced by this sample of studies, considerable literature over the years concerning statistics anxiety have revolved around factors such as academic outcomes, study habits, and instructional variables (e.g. Chiesi \& Primi, 2010; Dykeman, 2011; Keeley, Zayac, \& Correia, 2008; Onwuegbuzie \& Daley, 1996; Onwuegbuzie \& Wilson, 2003; Pan \& Tang, 2005; Zare, Rastegar, \& Hosseini, 2011). There have been fewer studies of the relationship between statistics anxiety and affective factors, though some do exist. For example, Onwuegbuzie (1998) explored two components of hope - agency and pathways - in relation to statistics anxiety in a sample of 109 graduate students. "Agency" is the part of hope that is derived from a sense of successful determination, and "pathways" refers to the perception of possessing successful strategies to attain a goal. A poor self-appraisal on either or on both of these elements will result in low levels of hope for goal attainment. Through canonical correlation, Onwuegbuzie examined the relationships among the two facets of hope and six types of statistics anxiety (the STARS instrument) and found a significant function that explained $18 \%$ of the shared variance $\left(r^{2}\right.$ $=0.18, p<0.05$ ) between the two variable sets. Additionally, correlations between the variables and canonical variates were all significant, indicating that both components of hope were significantly related to all six types of statistics anxiety. Therefore, the author concluded that students who have lower levels of hope also experience higher levels of statistics anxiety.

In continuing the study of affective factors, Onwuegbuzie and Daley (1998) approached the connection between statistics anxiety and perfectionism. After operationalizing perfectionism as neurotic perfectionism, wherein a person holds 
unreasonably high standards for him/herself and others while allowing no room for mistakes, the authors surveyed 107 graduate students concerning their levels of perfectionism in three areas: self, other, and socially-prescribed. Those who score high in self-oriented perfectionism expect perfection mainly in themselves, other-oriented perfection is aimed mainly at others, and socially-prescribed perfectionism relates to the belief that others hold rigidly high standards for them. Additionally, the students were surveyed about their levels of anxiety on six types of statistics anxiety (by the STARS instrument).

Through canonical correlation, the authors found that the two sets of variables shared a variance of $13.6 \%\left(r^{2}=0.136, p<0.05\right)$ with other-oriented perfectionism $\left(r^{2}=0.36\right)$ and socially-prescribed perfectionism $\left(r^{2}=0.76\right)$ contributing most substantially. Among the anxiety variables, interpretation anxiety $\left(r^{2}=0.50\right)$, computation self-concept $\left(r^{2}=\right.$ $0.14)$, and fear of asking for help $\left(r^{2}=0.68\right)$ made relevant contributions to the predictive model. Consequently, the authors concluded that other-oriented and socially-prescribed perfectionism predicted three types of statistics anxiety. In other words, when students held unreasonably high standards for others, and believed that others held those same standards for them, their anxiety levels were higher than students who did not hold such beliefs.

In a third study, the same author probed the relationship between statistics anxiety and procrastination. Onwuegbuzie (2004) utilized 135 graduate students to explore the link between two facets of procrastination (fear of failure and task aversiveness) and six types of statistics anxiety. The author found that procrastination is a problem, with $41.7 \%$ of the students reporting procrastinating on writing term papers, $39.3 \%$ on studying for tests, and $60.0 \%$ on reading assignments for class. Canonical correlation analysis showed that $6.8 \%\left(r^{2}=0.068, p<0.05\right)$ of the variance was shared between the procrastination and statistics anxiety variable sets, with fear of failure $\left(r^{2}=0.76\right)$ and task aversiveness $\left(r^{2}=0.59\right)$ both being important contributors, and all six types of statistics anxiety contributing substantially to the model as well. Based on these findings, it appears that students who procrastinate due to fear of failure and disdain for the tasks posed to them tend to experience higher levels of statistics anxiety.

Though studies such as these are certainly important in identifying affective variables related to statistics anxiety, it seems evident that variables such as hope, perfectionism, and procrastination are all manifestations of worry. In a recent approach to studying more basic aspects of worry in relation to statistics anxiety, Williams (2013) explored the relationship between worry, intolerance of uncertainty, and statistics anxiety. Using a sample of 97 graduate students, the author found that worry was significantly related to intolerance of uncertainty $(r=0.55, p<0.05)$, and was also related to three types of statistics anxiety (interpretation anxiety, $r=0.32$; test and class anxiety, $r=0.38$; computation self-concept, $r=0.32, p<0.05$ ).

According to these results, worry appears to be associated with both statistics anxiety and intolerance of uncertainty. Therefore, students who worry more tend to have a lower tolerance for unpredictability, which is common in statistics, and higher levels of anxiety. The author also provides evidence that students' levels of anxiety decreased significantly by course end but their tendencies toward intolerance of uncertainty and worry did not. This finding makes sense, as statistics anxiety is inclined to be a state-anxiety while intolerance of uncertainty and the tendency to worry are dispositional characteristics (Koerner \& Dugas, 2006). Even so, intolerance of uncertainty and tendency to worry may be amenable to certain modifications (Dugas \& Ladouceur, 2000; Ladouceur, Gosselin, \& Dugas, 2000). 


\subsection{WORRY AND INTOLERANCE OF UNCERTAINTY}

Worry is defined as an anxious apprehension of expected negative events (Barlow, 2002) that involves negative mental verbalization and imagery (Borkovec, Ray, \& Stober, 1998) and is the main characteristic of generalized anxiety disorder according to the Diagnostic and Statistical Manual of Mental Disorders (DSM-IV; American Psychiatric Association, 2000; Barlow, 2002). Research has indicated that generalized anxiety is perpetuated by a personal proclivity toward intolerance of uncertainty (e.g., Borkovec, Robinson, Pruzinsky, \& DePree, 1983; Tallis \& Eysenck, 1994), which has been defined as "a dispositional characteristic that results from a set of fundamental beliefs about uncertainty [wherein] individuals believe that uncertainty is stressful and upsetting, that being uncertain about the future is unfair, that unexpected events are negative and should be avoided, and that uncertainty interferes with one's ability to function" (Koerner \& Dugas, 2006, p. 202). There is evidence that those who are more intolerant of uncertainty may process information differently than those who are more tolerant (Dugas, Hedayati, Karavidas, Buhr, Francis, \& Phillips, 2005; Hedayati, Dugas, Buhr, \& Francis; 2003).

For example, in a two-part work conducted by Dugas et al. (2005), part one of the study centered on the goal of ascertaining whether intolerance of uncertainty is related to better recall of ambiguous information. One-hundred-one undergraduates were given two lists of fifteen words each. One list represented words that were deemed ambiguous in pilot studies, and the other list was comprised of matched neutral words (e.g., "maybe" for the ambiguous list matched with "above" for the neutral list). Immediately after, the students were asked to write as many words as they could remember, and then they were assessed for both tendency to worry and intolerance of uncertainty. After assessment, student scores were grouped according to high intolerance or low intolerance. Two-way ANOVA indicated a significant interaction between group and word type $(F(1,99)=4.30$, $p<0.05)$, one main effect for word type $(F(1,99)=32.93, p<0.001)$, but no main effect for group, thus indicating that all students, regardless of group, were able to remember a similar number of words, but those in the high intolerance of uncertainty group remembered significantly more ambiguous words than neutral words. Ratios per group were then calculated, and the researchers found that $63 \%$ of the words remembered in the high intolerance group were the ambiguous words as opposed to $57 \%$ in the low intolerance group, a significant $(t(99)=2.05, p<0.05)$ finding.

In part two of the authors' study, intended to investigate the relationship between intolerance of uncertainty and interpretation of ambiguous situations, 148 students were assessed for intolerance of uncertainty, worry, depression, and general anxiety, and given the ambiguous subscale of the Ambiguous/Unambiguous Situations Diary (Davey, Hampton, Farrell, \& Davidson, 1992). This instrument consists of fictitious situations that students are asked to interpret. Students who made the more threatening interpretations were expected to be more worrisome, intolerant of uncertainty, and depressed. Through hierarchical regression, the authors found that anxiety and depression explained $12 \%$ of the variance, worry explained an additional $3 \%$, and intolerance of uncertainty explained another $11 \%$ of the variance in concern for ambiguous information. This indicates that students who tend to construe ambiguous situations as more threatening also have a stronger tendency to be anxious, depressed, worrisome, and intolerant of uncertainty.

To summarize, both parts of this study support the contention that students who are higher in intolerance of uncertainty are more likely to remember ambiguous information more readily, as well as interpret it in more threatening ways. As indicated, intolerance of uncertainty appears to promote worry, and according to Koerner and Dugas (2006), this 
may be because of a relationship with positive beliefs about worry, negative problem orientation, and cognitive avoidance.

\subsection{POSITIVE BELIEFS ABOUT WORRY, NEGATIVE PROBLEM ORIENTATION, AND COGNITIVE AVOIDANCE}

According to Koerner and Dugas (2006), as individuals worry, their positive beliefs about worry are reinforced in two ways. First, if the worried-about event does not occur, then worry is seen to have prevented it. Alternately, if a solution is found to a problem, then it appears that worrying generated the solution. In this manner, worry can be viewed by the worrier as a positive trait (Bakerman, Buhr, Koerner, \& Dugas, 2004). In a joint study, Francis and Dugas (2004) explored the relationship between worry and positive beliefs about worry. Using a sample of 128 undergraduate students, measures of worry, anxiety, depression, and cognitive distortions were administered, as well as a structured interview on beliefs about worry consisting of a predetermined list of open-ended questions.

A hierarchical regression was used to assess the relationship between worry and positive beliefs about worry, while holding the other measured variables constant. Demographic variables were entered in the first step, with depression and anxiety making up the second, and worry was entered in the third step. The results showed that after the adjustments for the other variables, worry alone shared 5\% of the variance with positive beliefs. These results are similar to an earlier study (Davey, Tallis, \& Capuzzo, 1996) wherein the authors found that the positive aspect of "worry promotes analytical thinking" was significantly related to worry $(r=0.25, p<0.001)$. Koerner and Dugas (2006) point out that a commonality among positive beliefs about worry is that worrying can at least help a person maintain control over their reactions to a threatening situation if not control over the situation itself.

When people are intolerant of uncertainty, they are often less effective in problem solving, which then increases their tendency to worry (Koerner \& Dugas, 2006). To illustrate, Davey, Jubb, and Cameron (1996) showed that those with lower confidence in problem-solving, an aspect of negative problem orientation, also reported an increase in catastrophic worrying. In carrying this line further, Dugas, Freeston, and Ladouceur (1997) then investigated the relationship between intolerance of uncertainty and negative problem orientation. In their sample of 285 undergraduate students, measures of worry, intolerance of uncertainty, problem solving, anxiety, and depression were administered.

In two hierarchical regression analyses intended to assess the relationship between intolerance of uncertainty and problem orientation in the prediction of worry, the first three steps were the same for both (the entrance of age and gender first, anxiety and depression second, problem solving skills third). In the first regression, intolerance of uncertainty was entered fourth and significantly predicted worry scores, accounting for $16.3 \%$ of the variance. Problem orientation was entered fifth, and significantly predicted worry, accounting for an additional $4.6 \%$ of the variance. In the second regression, problem orientation was entered fourth, and shared $15.3 \%$ of the variance in worry. Intolerance of uncertainty was entered last, and shared $5.6 \%$ of the variance with worry. These results indicate that even after controlling for gender and age, anxiety, and depression, intolerance of uncertainty and problem orientation were both significant predictors of worry.

Cognitive avoidance is also recognized as a factor in worry. Sibrava and Borkovec (2006) postulate that worry functions as a means of avoidance in that when people worry they are mentally searching for ways either to avoid the perceived threat or to prepare for 
it if it is unavoidable. Further, the authors believe that worry functions as a cognitive avoidance response to upsetting thoughts or emotions. Other authors (Koerner \& Dugas, 2006; Sexton \& Dugas, 2009) propose that those who worry more may use a multitude of cognitive avoidance strategies in order to deflect distressing thoughts. To explore this conjecture, Sexton and Dugas (2009) surveyed 259 students concerning worry and cognitive avoidance in five areas: thought suppression, thought substitution, distraction, avoidance of threatening stimuli, and transformation of images into thoughts. They also included the variables of negative beliefs about worry, negative consequences of worry, fear of anxiety, and anxiety sensitivity. Correlations revealed that all of the cognitive avoidance strategies were significantly related to fear of anxiety, negative beliefs about worry, and worry.

In order to separate the individual contributions made by fear of anxiety and negative beliefs about worry in the prediction of cognitive avoidance, the authors conducted two hierarchical regressions with age and gender entered on the first step of each. The first regression indicated that negative beliefs about worry was predictive of cognitive avoidance $\left(r^{2}=0.42, p<0.001\right)$ in the second step, as was fear of anxiety $\left(r^{2}=0.03, p<\right.$ $0.001)$ in the third. In the second regression, fear of anxiety was entered second and was a significant predictor of cognitive avoidance $\left(r^{2}=0.33, p<0.001\right)$ while negative beliefs about worry was entered third and also predicted cognitive avoidance $\left(r^{2}=0.12, p<\right.$ 0.001). These results indicate that negative beliefs about worry predict cognitive avoidance after controlling for fear of anxiety, while anxiety sensitivity was able to predict cognitive avoidance after controlling for negative beliefs about worry.

As previous research indicates, not only are intolerance of uncertainty and worry related, but positive beliefs about worry, negative problem orientation, and cognitive avoidance also appear to figure prominently into our understanding of worry. Though most of the previously discussed literature applies to generalized anxiety, other forms of anxiety have also been linked to worry and other related variables (see Zeidner \& Matthews, 2011). One previous study has indicated a relationship between statistics anxiety, worry, and intolerance of uncertainty (Williams, 2013), but the other variables proposed by Koerner and Dugas (2006) to be part of this relationship have yet to be explored. Therefore, the current study aims to extend the Williams (2013) study by considering the relationship between worry and intolerance of uncertainty with the addition of positive beliefs about worry, negative problem orientation, and cognitive avoidance as they relate to statistics anxiety.

\subsection{PURPOSE OF THE STUDY}

If it is true that positive beliefs about worry, negative problem orientation, and cognitive avoidance are part of the relationship between intolerance of uncertainty, worry, and anxiety, then altering one or more of these additional affects may result in a beneficial change for the anxious student. For example, if students' advisors and/or instructors can regularly challenge students' beliefs that worry is beneficial (positive beliefs about worry), that statistics classes are a burden to be suffered (negative problem orientation), and that statistics should be dealt with when only necessary such as within the confines of statistics class (cognitive avoidance), these may be altered with a resulting decrease in their worry and statistics anxiety.

An example of such an alteration was demonstrated by Schacht and Stewart (1990, 1992) when they introduced humor into their classroom lectures. Using humor, the authors demonstrated that although students perceive statistics to be challenging, they can be influenced to perceive it as fun and interesting rather than tedious (i.e., a reduction of 
negative problem orientation). The authors report that as students became more engaged in these examples (i.e. a reduction of cognitive avoidance), their anxiety decreased. Lesser and Pearl (2008) suggest very much the same approach, with the addition of music and games about statistics, as ways to decrease anxiety for the facilitation of learning.

With a similar goal in mind, the current study is meant to extend Williams' (2013) research in an effort to uncover a multivariate relationship between the original three variables and three new variables. In Williams' study, the author found evidence of a relationship between intolerance of uncertainty, worry, and statistics anxiety, but this appears to be incomplete. In light of Koerner and Dugas' (2006) proposition that intolerance of uncertainty promotes worry because of its relationship with positive beliefs about worry, negative problem orientation, and cognitive avoidance, it seems that a more intricate picture of affective factors influencing graduate students' statistics anxiety may be indicated.

If the relationship between intolerance of uncertainty, worry, and statistics anxiety includes the additional variables of positive beliefs about worry, negative problem orientation, and cognitive avoidance, it will potentially bring about new affective interventions to help reduce students' anxiety.

\section{METHOD}

\subsection{PARTICIPANTS}

During the fall and spring semesters of the 2011-2012 academic year, student participants were recruited for the current study from the college of education in a large Southwestern university. All students were enrolled in three sections of a graduate introductory statistics course, and all $(N=103)$ volunteered to participate. Sixty were female (58.3\%), 64 (62.1\%) reported their ethnicity as white/Anglo, and 59 (57.3\%) were doctoral students with a mean age of 31.36 years for the sample. Most of the sample (82.8\%) was more than halfway through their degree programs, with $62.1 \%$ reporting less than 33 credit hours remaining. Enrollment records indicate a variety of majors represented: educational psychology, sports psychology, counseling, nutritional sciences, family/consumer sciences, higher education, and counseling. Table 1 presents the demographic characteristics of the participants.

Table 1. Demographics of graduate students in study $(n=103)$

\begin{tabular}{lrrrr}
\hline & $n$ & $\%$ & mean & $S D$ \\
\hline Male & 43 & 41.7 & & \\
Female & 60 & 58.3 & & \\
White & 64 & 62.1 & & \\
Asian & 15 & 14.6 & & \\
Hispanic & 13 & 12.6 & & \\
African- & 5 & 4.9 & & \\
American & 6 & 5.8 & & \\
Other ethnicity & 103 & & 31.36 & 10.64 \\
Age & 44 & 42.7 & & \\
Masters level & 59 & 57.3 & & \\
Doctoral level & 59 & & & \\
\hline
\end{tabular}




\subsection{INSTRUMENTS AND PROCEDURE}

The Statistics Anxiety Rating Scale (STARS) (Cruise, Cash, \& Bolton, 1985) was used to assess statistics anxiety. This 51-item instrument consists of six dimensions designed to gauge anxiety in these areas: worth of statistics, interpretation anxiety, test/class anxiety, computation self-concept, fear of asking for help, and fear of statistics teachers. Depending on the item, the 5-point Likert scales used for each time range from "strongly disagree" to "strongly agree" or from "no anxiety" to "high anxiety".

Worth of statistics asks about students' perceptions of the benefits of statistics both in their academic and future professional lives. Students who score higher on this dimension see little usefulness in statistics and tend to have a negative attitude toward statistics. A sample item is "I don't see why I have to clutter up my head with statistics. It has no significance to my life work".

The second dimension is interpretation anxiety and is used to evaluate students' anxiety over making statistical decisions or interpreting statistical outcomes. Students who score higher on this dimension experience more anxiety when trying to understand the results of analyses; this variable is measured by responses to items such as "Figuring out whether to reject or retain the null hypothesis".

Test/class anxiety measures students' levels of anxiety concerning statistics tests as well as classroom experiences. Students scoring higher on this dimension feel more anxiety not only in testing situations, but also when doing homework, preparing for class, and being in class. A sample item phrase reflecting this type of anxiety is "Walking into the classroom to take a statistics class".

The fourth dimension, computation self-concept, reflects students' anxiety when doing mathematics problems, and also measures their attitude toward mathematics. Students who score higher on this variable may not be especially anxious over statistics, but may feel more anxiety because of the mathematical calculations involved. Sample items for this dimension include "I haven't had math for a long time. I know I'll have problems getting through statistics" and "I could enjoy statistics if it weren't so mathematical”.

Fear of asking for help and fear of statistics teachers are similar, though separate, dimensions of anxiety. Fear of asking for help taps the students' anxiety about asking classmates or the professor for help understanding statistics material and concepts, while fear of statistics teachers indicates the students' perception of whether the instructor can relate to students as a human being. Sample items include "Asking a fellow student for help in understanding a printout" (fear of asking for help) and "Statistics teachers are so abstract they seem inhuman" (fear of statistics teachers). Those who score higher on these two variables experience more anxiety when seeking help and view statistics teachers as fearful or unapproachable.

Cruise, Cash, and Bolton (1985) reported test-retest reliability for the six dimensions ranging from 0.67 to 0.80 , and internal consistency reliabilities ranging from 0.68 to 0.94 , as well as construct validity evidence for the instrument resulting in factor loadings for the 51 retained items of 0.50 or greater for the six factors. In the current study, Cronbach's reliability coefficients for the six subscales were 0.94 (worth of statistics), 0.88 (interpretation anxiety), 0.93 (test and class anxiety), 0.90 (computation selfconcept), 0.89 (fear of asking for help), and 0.82 (fear of statistics teachers).

The Intolerance of Uncertainty Scale-12 (IUS-12) (Carleton, Norton, \& Asmundson, 2007) was used to measure students' tolerance for uncertainty. Twelve items, measured on a five-point Likert scale ranging from strongly disagree to strongly agree, are summed for a total intolerance score. Students scoring higher on the scale tend to exhibit less 
tolerance for uncertain situations. Sample items include "I can't stand being taken by surprise" and "The smallest doubt can stop me from acting". The original 27-item French version (Freeston, Rhéaume, Letarte, Dugas, \& Ladouceur, 1994) was shortened to create this 12-item instrument. Factor analysis provided structural validity evidence, indicating that the instrument measures two factors. Additionally, the instrument showed an internal consistency reliability coefficient of 0.91 (Carleton et al., 2007). For the current study, Cronbach's alpha reliability coefficient for the IUS-12 scale was 0.86 .

The Penn State Worry Questionnaire (PSWQ) (Meyer, Miller, Metzger, \& Borkovec, 1990) was used as a measure of students' tendency to worry. The instrument's 16 items are measured along a five-point Likert scale, and after summing, higher scores indicate a greater tendency toward worry. Sample items include "I am always worrying about something" and "Once I start worrying, I cannot stop". The results of factor analysis conducted by the instrument's authors provided evidence for a one-factor solution, with item loading ranging from 0.30 to 0.73 . Internal consistency for the 16 items was indicated with a coefficient of 0.93. For the current study, Cronbach's alpha reliability coefficient for the PSWQ was 0.94.

The Positive Consequences of Worry (PCW) subscale of the Consequences of Worrying Scale (COWS) (Davey, Tallis, \& Capuzzo, 1996) was used to assess students' positive beliefs about worry. The 12 items are measured on a five-point Likert scale, with higher mean scores indicating a stronger belief in worrying as a positive activity. The items are broken into two factors with one factor addressing motivational benefits of worry and the other addressing positive analytic thinking benefits of worry. Sample items include "In order to get something done I have to worry about it" (Worry Motivates) and "By worrying, I reorganize and plan my time better - if I stick to it, it makes me feel better” (Worry Helps Analytic Thinking).

The authors provided structural validity evidence via factor analysis, with the results indicating the presence of two underlying factors (or latent traits). The 6 items on motivational effects, with loadings from 0.51 to 0.71 , accounted for $49.1 \%$ of the variance while the 6 items on positive analytic thinking effects, with loadings from 0.51 to 0.68 , accounted for the remaining $8.5 \%$ of the variance. Cronbach's alpha reliability coefficients for the two factors were 0.85 for Worry Motivates and 0.72 for Worry Helps Analytic Thinking. For the current study, Cronbach's alpha reliability coefficients were 0.86 for Worry Motivates and 0.85 for Worry Helps Analytic Thinking. The total scale reliability for the 12 items was 0.90 , and students' scores were combined into one Positive Beliefs about Worry score.

The Negative Problem Orientation Questionnaire (NPOQ) (Robichaud \& Dugas, 2005) was used to determine students' tendency toward unproductive problem-solving attitudes. This attitude would reflect viewing problems as a personal threat, poor problem-solving efficacy, and poor outcome expectations. The instrument includes 12 questions measured along a 5-point Likert scale, with higher means indicating a greater tendency toward a negative orientation. Sample items include "I often doubt my capacity to solve problems" and "Even if I have looked at a problem from all possible angles, I still wonder if the solution I decide on will be effective". The authors provided structural validity evidence via factor analysis, supporting a one-factor solution that accounts for $54.8 \%$ of the variance and has item factor-loadings ranging from 0.64 to 0.79 . The instrument showed respectably high test-retest reliability $(r=0.80, p<0.01)$ and an internal consistency coefficient of 0.92 . For the current study, the NPOQ had a Cronbach's alpha reliability coefficient of 0.93 .

The English version of the Cognitive Avoidance Questionnaire (CAQ) (Sexton \& Dugas, 2008) was used to determine students' tendency toward cognitive avoidance. The 
instrument is designed to measure cognitive avoidance tendencies in the five areas of thought suppression, thought substitution, distraction, avoidance of threatening stimuli, and the transformation of images into thoughts. The 25 items are measured along a fivepoint Likert scale ranging from "not at all typical" to "completely typical" with higher total scores indicating a stronger tendency toward cognitive avoidance of perceived threatening thoughts. Sample items include "I try not to think about the most upsetting aspects of some situations so as not to be too afraid" and "I think about trivial details so as not to think about important subjects that worry me." The authors offer support for criterion validity through correlations with two established instruments designed to measure worry ( $r=0.64$ and $0.57, p<0.05$ ), and one measure of thought suppression $(r=$ $0.68, p<0.001)$. Reliability of the instrument was shown with a Cronbach's alpha of 0.95 and test-retest reliability at $(r=0.85)$. For the current study, the CAQ had a Cronbach's alpha coefficient of 0.93 .

On the first day of class of the single fall semester section and the two spring semester sections, graduate students attending introductory statistics class were asked for consent to participate in the study. The students were informed of the nature of the study and told that their opinions concerning statistics anxiety and various aspects of worry would be assessed. Confidentiality and anonymity were assured, and all students agreed to participate. So as not to influence students' opinions, all were given a paper questionnaire containing the instruments of interest and demographics questions before passing out syllabi and before any statistics instruction. All questionnaires were completed and returned to the investigator within the first 20 minutes of class.

\subsection{DATA ANALYSIS}

Canonical correlation analysis (CCA) was used to identify these worry variables that are correlated with the statistics anxiety dimensions. Onwuegbuzie (1998) utilized this analytical approach in his study examining the relationship between two components of hope and the six dimensions of statistics anxiety, when exploring the relationship between the components of perfectionism and the six dimensions of statistics anxiety (Onwuegbuzie \& Daley, 1998), and again in his study on the relationship between two types of procrastination and the same six dimensions of statistics anxiety (Onwuegbuzie, 2004). In all of these studies, the relationships within each variable set were not expected to be causal. For example, in the Onwuegbuzie (1998) study of the relationship between hope and statistics anxiety, the variables of agency and pathways were related because they are both components of hope. One is not expected to occur before or after the other because they are simultaneous facets of the same construct. Similarly, the six dimensions of statistics anxiety (Cruise, Cash, \& Bolton, 1985) are also simultaneous facets of the construct of statistics anxiety.

In the current study, the variables of positive beliefs about worry, negative problem orientation, and cognitive avoidance are all part of intolerance of uncertainty, which is an aspect of worry (Koerner \& Dugas, 2006). The relationship among these variables is not expected to be causal but rather a simultaneous occurrence of affective variables that are all related to anxiety. In the current study, this set of variables is expected to be related to the variable set of the six dimensions of statistics anxiety. Because the present study is similar in design to the previously mentioned studies (i.e., exploring the relationship between two sets of related variables), an analysis via structural equation modeling (SEM) were appropriate. However, as the sample size is smaller than required for such techniques, CCA appears to be the most appropriate analytical approach. According to Sherry and Henson (2005), canonical correlation analysis is the preferred method for 
detecting relationships between two sets of related variables for two reasons: 1) the multivariate nature of CCA decreases the risk of Type I error (the risk of finding interrelations significant while they do not exist) since the variables are compared simultaneously so that no corrections of $p$ values for multiple comparisons are required, and 2) the technique is consistent with the intent of psychological research that typically investigates multiple causes and effects. CCA can be considered as an elaborate form of bivariate correlation in that the procedure assesses the relationship between two synthetic variables that are formed from the two variable sets based on the inter-correlations within each set.

In the current study, the five worry variables were used as one variable set, and the six statistics anxiety dimensions were used as the other variable set. The number of canonical functions (i.e., pairs of synthetic variables) that can be formed during the analysis is equal to the number of variables in the smaller set (Sherry \& Henson, 2005). This means that there will be a maximum of five canonical functions in our study. As long as the canonical correlation for the first function is not perfect (i.e., 1.00), the functions that follow are an attempt to explain the remaining variance until either the remaining variance is explained or the five possible functions are formed. For the current study, standardized canonical function coefficients were computed. These are weighted values that are applied to each variable in a variable set to form the synthetic variable used in the canonical correlation. Structure coefficients were also computed, which give the correlations between the variables in a set and the synthetic variable for that set. Additionally, the squared structure coefficients are computed as a means of indicating the variance shared between each variable in the set and the synthetic variable for that set.

\section{RESULTS}

Bivariate correlations between the worry variables and the statistics anxiety dimensions are displayed in Table 2. Even though quite a few correlations are tested for significance and some researchers would adjust the $p$ values (by, e.g., Bonferroni) to minimize the risk of Type I errors, Perneger (1998) points out that such adjustments tend to increase Type II errors (as a result of the correction, the chance to find statistically significant relations drops drastically even if they apply). Therefore, in heeding this advice and considering the likelihood that relationships between variables would not be recognized, no adjustments were made for the $p$ values. Certainly in this case, the significance of very low correlations should be interpreted cautiously (Perneger, 1998).

With few exceptions, all five worry variables were significantly related to four of the statistics anxiety dimensions. None of the worry variables were significantly related to worth of statistics or fear of statistics teachers; intolerance of uncertainty showed no significant relationship with computation self concept, and positive beliefs about worry and cognitive avoidance were not significantly related to fear of asking for help.

In order to test the multivariate shared relationship between statistics anxiety and the worry variables, a canonical correlation analysis was performed using the worry variables (worry, intolerance of uncertainty, positive beliefs about worry, negative problem orientation, and cognitive avoidance) and the six STARS dimensions of statistics anxiety (worth of statistics, interpretation anxiety, test/class anxiety, computation self-concept, fear of asking for help, and fear of statistics teachers). Five functions were revealed with respective squared canonical correlations $\left(R_{c}{ }^{2}\right)$ of $0.31,0.07,0.02,0.01$, and 0.00 . Only the first function, which represents the full model across all functions, was significant $(\lambda$ $=0.62, F(30,370)=1.59, p=0.028)$, indicating a relationship between the two variable sets. In utilizing Wilks' $\lambda$ as a measure of unexplained variance, $1-\lambda$ gives an $r^{2}$-type 
estimation of the full model effect size. In this sense, the full model explains 38\% of the variance shared between the worry variables and the statistics anxiety dimensions.

Table 2. Pearson's $r$ correlations among research variables

\begin{tabular}{lrlllll}
\hline \multicolumn{1}{c}{ Worry Variables } & \multicolumn{5}{c}{ STARS Dimension } \\
& WS & IA & TCA & CSC & FAH & FST \\
\hline Worry & 0.15 & $0.36^{* *}$ & $0.44^{* *}$ & $0.26^{* *}$ & $0.33^{* *}$ & 0.17 \\
Intolerance of Uncertainty & 0.05 & $0.30^{* *}$ & $0.27^{* *}$ & 0.11 & $0.24^{*}$ & 0.06 \\
Positive Beliefs About Worry & -0.04 & $0.25^{*}$ & $0.26^{* *}$ & $0.21^{*}$ & 0.15 & 0.15 \\
Negative Problem Orientation & 0.11 & $0.38^{* *}$ & $0.39^{* *}$ & $0.27^{* *}$ & $0.34^{* *}$ & 0.14 \\
Cognitive Avoidance & 0.01 & $0.28^{* *}$ & $0.26^{* *}$ & $0.23^{*}$ & 0.19 & 0.14 \\
\hline
\end{tabular}

Note: WS: Worth of Statistics; IA: Interpretation Anxiety; TCA: Test/Class Anxiety; CSC: Computation Self-Concept; FAH: Fear of Asking for Help; FST: Fear of Statistics Teacher ${ }^{*} p<0.05 ;{ }^{* *} p<0.01$

Dimension reduction analysis tests the hierarchical organization of the functions for significance. As previously mentioned, the full model (functions 1-5) was significant. The remaining function groups were not statistically significant with significance values ranging from $p=0.95$ to 0.99 (see Table 3 ). Therefore, no attempt was made to reduce the full model and only the first function was interpreted.

Table 3. Dimension reductions for the five function hierarchies

\begin{tabular}{cccc}
\hline $\begin{array}{c}\text { Function } \\
\text { Hierarchies }\end{array}$ & Wilks's $\lambda$ & $F(d f 1, d f 2)$ & $p$ value \\
\hline 1 to 5 & 0.62 & $1.59(30,370)$ & 0.028 \\
2 to 5 & 0.89 & $0.54(20,310)$ & 0.947 \\
3 to 5 & 0.96 & $0.30(12,249)$ & 0.990 \\
4 to 5 & 0.99 & $0.14(6,190)$ & 0.991 \\
5 to 5 & 0.99 & $0.02(2,96)$ & 0.979 \\
\hline
\end{tabular}

The standardized canonical function coefficients, structure coefficients, and squared structure coefficients for the full model are presented in Table 4. In using the correlation of 0.30 as the recommended minimum value for inclusion (Lambert \& Durand, 1975) the variables of worth of statistics, computation self concept, and fear of statistics teachers, due to their small standardized canonical coefficients, appear to contribute little to the first function. However, all of the anxiety variables except for worth of statistics made relevant contributions to the synthetic anxiety variable as evidenced by the structure coefficients. This is further supported by the squared structure coefficients, with worth of statistics contributing only minimally to the synthetic anxiety variable.

Among the worry variables, intolerance of uncertainty, positive beliefs about worry, and cognitive avoidance showed low standardized canonical coefficients. Even so, the variables show larger structure coefficients and provide respectable contributions to the synthetic worry variable. Variables with low structure coefficients but relatively larger standardized coefficients are said to be suppressor variables, meaning that they help support the relationship between the two synthetic variables by way of their correlations with other variables in their own set (Tabachnick \& Fidell, 2007). Since all of the worry variable structure coefficients were 0.30 or larger, none of the variables appear to have served as suppressor variables. Further, the squared structure coefficients show that all of the worry variables contributed substantially to the synthetic anxiety variable with worry 
and negative problem orientation explaining the majority of the variance. Collectively, these results indicate the presence of a relationship between the worry variables and the dimensions of statistics anxiety.

Table 4. Canonical solution for worry variables predicting statistics anxiety for the full model

\begin{tabular}{lccr}
\hline Dimensions of statistics anxiety & Coeff & $r_{s}$ & $r_{s}{ }^{2}(\%)$ \\
\hline Worth of Statistic & 0.110 & -0.185 & 3.42 \\
Interpretation Anxiety & $-0.314^{*}$ & $-0.813^{*}$ & 66.10 \\
Test/Class Anxiety & $-0.561^{*}$ & $-0.893^{*}$ & 79.75 \\
Computation Self Concept & -0.101 & $-0.626^{*}$ & 39.19 \\
Fear of Asking for Help & $-0.351^{*}$ & $-0.666^{*}$ & 44.36 \\
Fear of Statistics Teachers & 0.085 & $-0.389^{*}$ & 15.13 \\
$R_{c}{ }^{2}$ & & & 30.96 \\
\hline \multicolumn{1}{c}{ Worry variables } & & & \\
\hline Worry & $-0.481^{*}$ & $-0.851^{*}$ & 72.42 \\
Intolerance of Uncertainty & 0.084 & $-0.590^{*}$ & 34.81 \\
Positive Beliefs About Worry & -0.291 & $-0.515^{*}$ & 26.52 \\
Negative Problem Orientation & $-0.412^{*}$ & $-0.823^{*}$ & 67.73 \\
Cognitive Avoidance & -0.273 & $-0.557^{*}$ & 31.03 \\
\hline
\end{tabular}

Note: Coeff $=$ standardized canonical function coefficient; $r_{s}=$ structure coefficient; $r_{s}^{2}=$ squared structure coefficient; * = loadings with effect sizes greater than 0.30

\section{DISCUSSION AND CONCLUSIONS}

The purpose of the current study was to extend previous research that evidenced a relationship between intolerance of uncertainty, worry, and statistics anxiety to include the additional variables of positive beliefs about worry, negative problem orientation, and cognitive avoidance. As Williams (2013) has indicated, students who have higher levels of intolerance of uncertainty also tend to worry more and have higher levels of statistics anxiety. By including three additional affective variables in the current study that other researchers (Koerner \& Dugas, 2006) have shown to be involved in general anxiety, a clearer idea of the complexity of statistics anxiety is offered.

The findings of this study should be thoughtfully received, however, due to the nature of the study, the limited sample, and the design and analysis chosen. Following is a discussion of the findings and the limitations of the current study, as well as suggestions for future research.

\subsection{SUMMARY OF FINDINGS AND RECOMMENDATIONS}

In an effort to increase awareness of the complexity of students' anxiety surrounding statistics education, the current study proposed the addition of three supplementary variables to Williams' (2013) findings of the relatedness of statistics anxiety, intolerance of uncertainty, and worry. The work of Koerner and Dugas (2006) had previously indicated that positive beliefs about worry, negative problem orientation, and cognitive avoidance also contribute to the experience of anxiety, leading to the inclusion of these variables in the attempt to add depth to current understanding of students' experience of statistics anxiety. The canonical correlation analysis indicated that worry, intolerance of 
uncertainty, positive beliefs about worry, negative problem orientation, and cognitive avoidance bore a relationship with six types of statistics anxiety (from the STARS instrument). In other words, students who worry more and believe that worry is beneficial are more likely to experience higher anxiety. Also, those who lack tolerance for uncertainty, view problems in a negative way, or engage in more cognitive avoidance are also likely to have higher levels of anxiety about statistics.

Recognizing the relationship between these variables is important in highlighting potential ports for influencing students' anxiety. In altering affective variables that are related to statistics anxiety, educators can potentially influence the experience of students. Such an alteration was achieved through direct manipulation of intolerance of uncertainty (Ladouceur, Gosselin, \& Dugas, 2000) in a sample of 42 undergraduates. Students were randomly assigned to either an "increase in intolerance" group or a "decrease in intolerance" group. As each group of students played the same gambling game, the "increase" group was repeatedly told their chances of winning were very low while the "decrease" group was told their chances of winning were very good. A $t$-test indicated that the "increase" group reported significantly higher levels of worry than did the "decrease group" $(t(40)=5.52, p<0.05)$, suggesting that intolerance of uncertainty can be directly manipulated, at least in college students, to reduce worrying.

Intolerance of uncertainty may be decreased also indirectly through the manipulation of positive beliefs about worry, negative problem orientation, and cognitive avoidance. To illustrate, Dugas and Ladouceur (2000) effectively reduced adults' intolerance of uncertainty through a process of awareness training and worry interventions. The authors implemented awareness training by having participants stop their activity whenever worries crossed their minds and write about those worries, which had the constructive effect of helping them discriminate between worries that could and could not be solved.

This laid the groundwork for worry interventions, one of which involved having participants consciously examine whether their worries were truly useful, and whether they were solvable, effectively addressing the main component of positive beliefs about worry. After re-evaluating their beliefs about worry, participants were encouraged to focus on a solvable problem, identifying major aspects of the problem while downplaying minor details, and proceeding to work out the problem even though the outcome was uncertain. This helped the participants develop a more positive problem orientation. Finally, problems that were not solvable were used for cognitive exposure through listening to tape recordings of the participants' own description of the problems. This exposure disrupted their tendency to engage in cognitive avoidance, reduced the perceived severity of the problem, and increased their tolerance for uncertainty by changing the subjective meaning of the problem.

These studies indicate that due to the relationship between intolerance of uncertainty and worry, positive beliefs about worry, negative problem orientation and cognitive avoidance, the manipulation of one or more of these affects reveals a change in one or more of the others. This is promising information for statistics instructors. Though the latter approach for indirectly reducing anxiety was used in a therapeutic context with generalized anxiety disordered individuals, a variation of the techniques may well be useful for graduate students dealing with the affective bad habits of positive beliefs about worry, negative problem orientation, and cognitive avoidance.

\subsection{LIMITATIONS}

Though the current study makes a potentially valuable contribution to the understanding of statistics anxiety, its limitations should also be considered. First, the 
study design is observational, meaning that the relationship between the variables is supported without any implied directionality or causality. For example, it would not be prudent to assume based on these results that students who worry and believe worry to be constructive are necessarily causing themselves additional anxiety, or that those who are highly anxious will then engage in more cognitive avoidance or will view problems more negatively. Though such causal relationships may exist, such contentions are beyond the scope of this study and the current results do not support such contentions. Only the cooccurrence of these affective variables is supported by the current findings.

Second, the study utilized a relatively small sample consisting of volunteers recruited from a single statistics course in one university, thereby appreciably limiting the generalizability of the findings. For example, though the sample was fairly equal in gender composition, the students were mainly Caucasian doctoral students, suggesting a need for replication of the study using more ethnic and academic diversity. The small sample size also limited the choice of analyses to those that are strictly correlational in nature, rather than the more desirable structural equation modeling (SEM) which would have been useful in helping to determine directionality and structure of the relationships between the study variables.

A third limitation involves the lack of control for potentially confounding variables. Canonical correlation indicates the extent to which variable sets are related, but does not account for the possibility of other variables that may be influencing or even responsible for the relationship. It is entirely conceivable that the relationship indicated by the current findings between worry variables and anxiety variables may be influenced by variables not included in the current study. For example, Bakerman, Buhr, and Dugas (2003) found evidence in a sample of college students that those who reported the highest tendency toward worry also reported higher fear of the experience of anxiety. Therefore, it is possible that fear of anxiety may play into and even alter the relationship between worry and statistics anxiety.

Finally, since all of the data collected was based on self-report, the possibility of students' desire to give socially acceptable answers to the questionnaires should also be considered. If social desirability influenced the students' reports, they may actually be experiencing more or less of the variables measured (e.g., higher levels of worry, which could be perceived as less socially acceptable) than indicated, which may in turn influence the relationships between the two variable sets.

\subsection{RECOMMENDATIONS FOR FUTURE RESEARCH}

In consideration of the limitations of the study, some indications for future research are warranted. Since it is unclear whether the relationship between the variables in this study is strictly correlational, or if there is some causal aspect or ordering of variables, it is recommended that future researchers replicate the current study using a larger, perhaps more diverse, sample. The larger sample size would allow the utility of SEM to reveal information concerning the directionality and structure of the relationships between variables, while the more diverse sample would provide information concerning the universality of the relationships, thereby improving generalizability. Further, researchers should consider the inclusion of additional affective variables, such as fear of affective experience, as such variables may add valuable insight to students' experience of statistics anxiety while reducing the incidence of confounding influence. Another consideration is the addition of a social desirability scale to detect the extent to which students answer self-report questions about affect without reservation. 
Additionally, further research should be conducted to probe interventions that challenge students' positive beliefs about worry, negative problem orientation, and cognitive avoidance concerning their statistics courses. For example, students could be assigned a journaling activity wherein they would write about their fears and worries concerning statistics. Instructors or instructors' assistants could ask students to determine how realistic their worries are (e.g., "I might fail the course and be thrown out of graduate school" vs. "I might fail the next test"), and discuss with them whether worrying will actually help the situation. They could also help students to focus on how to solve the problem and discuss these solutions with them (e.g., effective study methods or obtaining a tutor). As students learn to cope with their fears, rather than try to control them through worrying, their intolerance of uncertainty and worrying should diminish with a corresponding lessening of their anxiety.

\section{REFERENCES}

American Psychiatric Association (2000). Diagnostic and statistical manual of mental disorders (4th ed., text rev.). Washington, DC: Author.

Bakerman, D., Buhr, K., \& Dugas, M. J. (2003, March). Examination of the relationship between worry and fear of emotional arousal and experiential avoidance. Paper presented at the national conference of the Anxiety Disorders Association of America, Toronto, ON.

Bakerman, D., Buhr, K., Koerner, N., \& Dugas, M. J. (2004, November). Exploring the link between positive beliefs about worry and worry. Paper presented at the annual convention of the Association for Advancement of Behavior Therapy, New Orleans, LA.

Barlow, D. H. (2002). Anxiety and its disorders: The nature and treatment of anxiety and panic (2nd ed.). New York: Guilford Press.

Bell, J. A. (1998). International students have statistics anxiety too! Education, 118(4), 634-636.

Bell, J. A. (2004). Statistics anxiety: The nontraditional student. Education, 124(1), 157162.

Benson, J. (1989). Structural components of statistical test anxiety in adults: An exploratory model. The Journal of Experimental Education, 57(3), 247-261.

Benson, J., Bandalos, D. L., \& Hutchinson, S. (1994). Modeling test anxiety among men and women. Anxiety, Stress, and Coping, 7(2), 131-148.

Blalock, H. M. (1987). Some general goals in teaching statistics. Teaching Sociology, 15(2), 164-172.

Borkovec, T. D., Hazlett-Stevens, H., \& Diaz, M. L. (1999). The role of positive beliefs about worry in generalized anxiety disorder and its treatment. Clinical Psychology and Psychotherapy, 6(2), 126-138.

Borkovec, T. D., Ray, W., \& Stober, J. (1998). Worry: A cognitive phenomenon intimately linked to affective, physiological, and interpersonal behavioral processes. Cognitive Therapy and Research, 22(6), 561-576.

Borkovec, T. D., Robinson, E., Pruzinsky, T., \& DePree, J. A. (1983). Preliminary exploration of worry: Some characteristics and processes. Behaviour Research and Therapy, 21(1), 9-16.

Borkovec, T. D., \& Roemer, L. (1995). Perceived functions of worry among generalized anxiety disorder subjects: Distraction from more emotional topics? Journal of Behavior Therapy and Experimental Psychiatry, 26(1), 25-30. 
Carleton, R. N., Norton, P. J., \& Asmundson, G. J. G. (2007). Fearing the unknown: A short version of the Intolerance of Uncertainty Scale. Journal of Anxiety Disorders, 21(1), 105-117.

Chiesi, F., \& Primi, C. (2010). Cognitive and non-cognitive factors related to students' statistics achievement. Statistics Education Research Journal, 9(1), 6-26.

[Online: http://iase-web.org/documents/SERJ/SERJ9(1)_Chiesi_Primi.pdf].

Cruise, R. J., Cash, R. W., \& Bolton, D. L. (1985). Development and validation of an instrument to measure statistical anxiety. Proceedings of the Joint Statistical Meetings, Section on Statistical Education (pp. 92-97). Alexandria, VA: American Statistical Association.

Davey, G. C. L., Hampton, J., Farrell, J., \& Davidson, S. (1992). Some characteristics of worrying: Evidence for worrying and anxiety as separate constructs. Personality and Individual Differences, 13(2), 133-147.

Davey, G. C. L., Jubb, M., \& Cameron, C. (1996). Catastrophic worrying as a function of changes in problem-solving confidence. Cognitive Therapy and Research, 20(4), 333-344.

Davey, G. C. L., Tallis, F., \& Capuzzo, N. (1996). Beliefs about the consequences of worrying. Cognitive Therapy and Research, 20(5), 499-520.

Demaria-Mitton, P. A. (1987). Locus-of-control, gender, and type of major as correlates to statistics anxiety in college students. Dissertation Abstracts International, 48, 1397A.

DeVaney, T. A. (2010). Anxiety and attitude of graduate students in on-campus vs. online statistics courses. Journal of Statistics Education, 18(1), 1-15.

[Online: http://www.amstat.org/publications/jse/v18n1/devaney.pdf ]

Dillon, K. M. (1982). Statisticophobia. Teaching of Psychology, 9(2), 117.

Dugas, M. J., Freeston, M. H., \& Ladouceur, R. (1997). Intolerance of uncertainty and problem orientation in worry. Cognitive Therapy and Research, 21(6), 593-606.

Dugas, M. J., Hedayati, M., Karadivas, A., Buhr, K., Francis, K., \& Phillips, N. A. (2005). Intolerance of uncertainty and information processing: Evidence of biased recall and interpretations. Cognitive Therapy and Research, 29(1), 57-70.

Dugas, M. J., \& Ladouceur, R. (2000). Treatment of GAD: Targeting intolerance of uncertainty in two types of worry. Behavior Modification, 24(5), 635-657.

Dykeman, B. F. (2011). Statistics anxiety: Antecedents and instructional interventions. Education, 132(2), 441-446.

Fitzgerald, S. M., \& Jurs, S. J (1996). A model predicting statistics achievement among graduate students. College Student Journal, 30(3), 361-366.

Francis, K., \& Dugas, M. J. (2004). Assessing positive beliefs about worry: Validation of a structured interview. Personality and Individual Differences, 37(2), 405-415.

Freeston, M. H., Rhéaume, J., Letarte, H., Dugas, M. J., \& Ladouceur, R. (1994). Why do people worry? Personality and Individual Differences, 17(6), 791-802.

Hedayati, M., Dugas, M. J., Buhr, K., \& Francis, K. (2003, November). The relationship between intolerance of uncertainty and the interpretation of a-366.mbiguous and unambiguous information. Poster presented at the annual convention of the Association for the Advancement of Behavior Therapy, Boston, MA.

Keeley, J., Zayac, R., \& Correia, C. (2008). Curvilinear relationships between statistics anxiety and performance among undergraduate students: Evidence for optimal anxiety. Statistics Education Research Journal, 7(1), 4-15.

[Online: http://iase-web.org/documents/SERJ/SERJ7(1)_Keeley.pdf ] 
Koerner, N., \& Dugas, M. J. (2006). A cognitive model of generalized anxiety disorder: the role of intolerance of uncertainty. In G. C. L. Davey \& A. Wells (Eds.), Worry and its psychological disorders: Theory, assessment, and treatment (pp. 201-216). West Sussex, England: John Wiley.

Lambert, Z. V., \& Durand, R. M. (1975). Some precautions in using canonical analysis. Journal of Market Research, 12(4), 468-475.

Ladouceur, R., Blais, F., Freeston, M. H., \& Dugas, M. J. (1998). Problem solving and problem orientation in generalized anxiety disorder. Journal of Anxiety Disorders, 12(2), 139-152.

Ladouceur, R., Gosselin, P., \& Dugas, M. J. (2000). Experimental manipulation of intolerance of uncertainty: A study of a theoretical model of worry. Behaviour Research and Therapy, 38(9), 933-941.

Lalonde, R. N., \& Gardner, R. C. (1993). Statistics as a second language? A model for predicting performance in psychology students. Canadian Journal of Behavioral Science, 25(1), 108-125.

Lesser, L. M., \& Pearl, D. K. (2008). Functional fun in statistics teaching: Resources, research and recommendations. Journal of Statistics Education, 16(3), 1-10.

[Online: www.amstat.org/publications/jse/v16n3/lesser.pdf ]

Meyer, T. J., Miller, M. L., Metzger, R. L., \& Borkovec, T. D. (1990). Development and validation of the Penn State Worry Questionnaire. Behaviour Research and Therapy, 28(6), 487-495.

Murtonen, M., \& Lehtinen, E. (2003). Difficulties experienced by education and sociology students in quantitative methods courses. Studies in Higher Education, 28(2), 171-185.

Onwuegbuzie, A. J. (1995). Statistics test anxiety and female students. Psychology of Women Quarterly, 19(3), 413-418.

Onwuegbuzie, A. J. (1997). Writing a research proposal: The role of library anxiety, statistics anxiety, and composition anxiety. Library and Information Science Research, 19(1), 5-33.

Onwuegbuzie, A. J. (1998). The role of hope in predicting statistics anxiety. Psychological Reports, 82(3), 1315-1320.

Onwuegbuzie, A. J. (2000a). Attitudes toward statistics assessments. Assessment and Evaluation in Higher Education, 25(4), 321-339.

Onwuegbuzie, A. J. (2000b, April). I'll begin my statistics assignment tomorrow: The relationship between statistics anxiety and academic procrastination. Paper presented at the annual meeting of the American Educational Research Association (AERA), New Orleans, LA.

Onwuegbuzie, A. J. (2000c). Statistics anxiety and the role of self-perceptions. The Journal of Educational Research, 93(5), 323-330.

Onwuegbuzie, A. J. (2003). Modeling statistics achievement among graduate students. Educational and Psychological Measurement, 63(6), 1020-1038.

Onwuegbuzie, A. J. (2004). Academic procrastination and statistics anxiety. Assessment and Evaluation in Higher Education, 29(1), 3-19.

Onwuegbuzie, A. J., \& Daley, C. E. (1996). The relative contribution of examinationtaking coping strategies and study coping-strategies to test anxiety: A concurrent analysis. Cognitive Therapy and Research, 20(3), 287-303.

Onwuegbuzie, A. J., \& Daley, C. E. (1999). Perfectionism and statistics anxiety. Personality and Individual Differences, 26(6), 1089-1102. 
Onwuegbuzie, A. J., DaRos, D., \& Ryan, J. (1997). The components of statistics anxiety: A phenomenological study. Focus on Learning Problems in Mathematics, 19(4), 1135.

Onwuegbuzie, A. J., \& Seaman, M. (1995). The effect of time constraints and statistics test anxiety on statistics achievement. Journal of Experimental Education, 63(2), $115-124$.

Onwuegbuzie, A. J., \& Wilson, V. A. (2003). Statistics anxiety: Nature, etiology, antecedents, effects, and treatments: A comprehensive review of the literature. Teaching in Higher Education, 8(2), 195-209.

Pan, W., \& Tang, M. (2005). Students' perceptions on factors of statistics anxiety and instructional strategies. Journal of Instructional Psychology, 32(3), 205-214.

Perepiczka, M., Chandler, N., \& Becerra, M. (2011). Relationship between graduate students' statistics self-efficacy, statistics anxiety, attitude toward statistics, and social support. The Professional Counselor, 1(2), 99-108.

Perneger, T. V. (1998). What's wrong with Bonferroni adjustments. British Medical Journal, 316(7139), 1236-1238.

Rachman, S. (2004). Anxiety (2nd ed.). East Sussex, UK: Psychology Press.

Roberts, D. M., \& Bilderback, E. W. (1980). Reliability and validity of a statistics attitude survey. Educational and Psychological Measurement, 40(1), 235-238.

Roberts, D. M., \& Saxe, J. E. (1982). Validity of a statistics attitude survey: A follow-up study. Educational and Psychological Measurement, 42(3), 907-912.

Robichaud, M., \& Dugas, M. J. (2005). Negative problem orientation (Part 1): Psychometric properties of a new measure. Behaviour Research and Therapy, 43(3), 391-401.

Ruscio, A. M., \& Borkovec, T. D. (2004). Experience and appraisal of worry among high worriers with and without generalized anxiety disorder. Behavior Research and Therapy, 42(12), 1469-1482.

Schacht, S., \& Stewart, B. J. (1990). What's funny about statistics? A technique for reducing student anxiety. Teaching Sociology, 18(1), 52-56.

Schacht, S., \& Stewart, B. J. (1992). Interactive/user-friendly gimmicks for teaching statistics. Teaching Sociology, 20(4), 329-332.

Sexton, K. A., \& Dugas, M. J. (2008). The cognitive avoidance questionnaire: Validation of the English translation. Journal of Anxiety Disorders, 22(3), 355-370.

Sexton, K. A., \& Dugas, M. J. (2009). An investigation of factors associated withcognitive avoidance in worry. Cognitive Therapy Research, 33(2), 150-162.

Sherry, A., \& Henson, R. K. (2005). Conducting and interpreting canonical correlation analysis in personality research: A user-friendly primer. Journal of Personality Assessment, 84(1), 37-48.

Sibrava, N. J., \& Borkovec, T. D. (2006). The cognitive avoidance theory of worry. In G. C. L. Davey \& A. Wells (Eds.), Worry and its psychological disorders: Theory, assessment, and treatment (pp. 239-256). West Sussex, England: John Wiley

Tabachnick, B. G., \& Fidell, L. S. (2007). Using multivariate statistics. Boston, MA: Pearson Education.

Tallis, F., \& Eysenck, M. W. (1994). Worry: Mechanisms and modulating influences. Behavioural and Cognitive Psychotherapy, 22(1), 37-56.

Williams, A. S. (2010). Statistics anxiety and instructor immediacy. Journal of Statistics Education, 18(2), 1-18.

[Online: http://www.amstat.org/publications/jse/v18n2/williams.pdf ] 
Williams, A. S. (2013). Worry, intolerance of uncertainty, and statistics anxiety. Statistics Education Research Journal, 12(1), 48-59.

[Online: http://iase-web.org/documents/SERJ/SERJ12(1)_Williams.pdf ]

Wilson, V. A. (1996). Factors related to anxiety in statistics (Unpublished doctoral dissertation). University of Southern Mississippi, Hattiesburg, MS.

Wilson, V. A. (1999, April). Student response to a systematic program of anxietyreducing strategies in a graduate-level introductory educational research course. Paper presented at the annual meeting of the American Educational Research Association, Montreal, Quebec.

Wise, S. L. (1985). The development and validation of a scale measuring attitudes toward statistics. Educational and Psychological Measurement, 45(2), 401-405.

Zanakis, S. H., \& Valenzi, E. R. (1997). Student anxiety and attitudes in business statistics. Journal of Education for Business, 73(1), 10-16.

Zare, H., Rastegar, A., \& Hosseini, S. (2011). The relation among achievement goals and academic achievement in statistics: the mediating role of statistics anxiety and statistics self-efficacy. Social and Behavioral Sciences, 30, 1166-1172.

Zeidner, M. (1991). Statistics and mathematics anxiety in social science students: Some interesting parallels. British Journal of Educational Psychology, 61(3), 319-328.

Zeidner, M., \& Matthews, G. (2011). Anxiety 101. New York: Springer.

AMANDA S. WILLIAMS

$300818^{\text {th }}$ Street

Lubbock, Texas 79409 